\title{
Selecting the optimal antithrombotic regimen for patients with acute coronary syndromes undergoing percutaneous coronary intervention
}

This article was published in the following Dove Press journal:

Vascular Health and Risk Management

18 August 2009

Number of times this article has been viewed

\author{
Shailja V Parikh' \\ Ellen C Keeley ${ }^{2}$ \\ 'Departments of Internal Medicine, \\ Divisions of Cardiology, University \\ of Texas Southwestern Medical \\ Center, Dallas, Texas, ${ }^{2}$ University \\ of Virginia, Charlottesville, \\ Virginia, USA
}

This work was supported by NIH grant HL097074 (Keeley)

Correspondence: Ellen C Keeley University of Virginia, Division of Cardiology, PO Box 800I58, Charlottesville, Virginia 22908-0158, USA

$\mathrm{Tel}+\mathrm{I} 434-924-2420$

Fax +| 434-924-258|

Email keeley@virginia.edu

\begin{abstract}
The wide variety of anticoagulant and antiplatelet agents available for clinical use has made choosing the optimal antithrombotic regimen for patients with acute coronary syndromes undergoing percutaneous coronary intervention a complex task. While there is no single best regimen, from a risk-benefit ratio standpoint, particular regimens may be considered optimal for different patients. We review the mechanisms of action for the commonly prescribed antithrombotic medications, summarize pertinent data from randomized trials on their use in acute coronary syndromes, and provide an algorithm (incorporating data from these trials as well as risk assessment instruments) that will help guide the decision-making process.
\end{abstract}

Keywords: anticoagulant, antiplatelet, percutaneous coronary intervention

\section{Introduction}

In the early days of percutaneous coronary intervention (PCI) the armamentarium of antithrombotic agents was limited; therefore, the decision on what agent(s) to administer was fairly straightforward. The wide variety of anticoagulant and antiplatelet agents available for clinical use now has made this decision-making process much more complex, and at times even confusing. While there is no single best choice for an antithrombotic regimen in patients with acute coronary syndromes (ACS) undergoing PCI, from a risk-benefit ratio standpoint, a particular regimen may be better for an individual patient. Because early invasive strategies with coronary angiography and PCI are preferred for certain patients with unstable angina, non-ST elevation myocardial infarction (STEMI), ${ }^{1-4}$ and STEMI, ${ }^{5}$ the scope of this issue is considerable. Nearly 8 million people are diagnosed with an ACS annually in the United States alone, and an estimated 1.3 million undergo a PCI procedure. ${ }^{6}$ Importantly, up to $15 \%$ of patients undergoing PCI develop a major bleeding complication, ${ }^{7,8}$ which results in higher rates of short- and long-term mortality. ${ }^{7,8}$ The evidence supporting a causal relationship between major bleeding and excess mortality in patients undergoing PCI (including the potential mechanisms involved) has been recently reviewed. ${ }^{9}$

Decisions on the choice of antithrombotic regimen, therefore, should be individualized, and take into consideration both the risk of a recurrent cardiac event as well as the risk of a bleeding complication. We will review the mechanisms of action for the commonly prescribed antithrombotic medications, summarize pertinent data from randomized trials regarding their use in ACS, and provide an algorithm that will help physicians choose the most effective and safest regimen for an individual patient with an ACS undergoing PCI. 


\section{Antithrombotic agents - mechanisms of action}

Patients presenting with ACS who undergo PCI benefit from a combination of antiplatelet and anticoagulant medications. ${ }^{10}$ From a pathophysiologic standpoint, the inciting event for an ACS is endothelial injury (plaque rupture or erosion): subsequent activation of platelets and the coagulation cascade results in thrombus formation. ${ }^{11,12}$ If this process is not interrupted, total occlusion of the coronary artery may occur, resulting in a myocardial infarction. Since platelet adhesion, activation, and aggregation comprise the initial stage in thrombus formation, antiplatelet agents (aspirin, thienopyridines, and platelet glycoprotein IIb/IIIa inhibitors) are critically important. Additionally, anticoagulant agents (indirect and direct thrombin inhibitors, and factor $\mathrm{Xa}$ inhibitor) also play a key role in the pathophysiologic process by limiting clot formation and propagation, particularly during the PCI procedure itself.

\section{Antiplatelet agents}

Antiplatelet medications (aspirin, thienopyridines, and platelet glycoprotein IIb/IIIa inhibitors) are commonly used alone or in combination with other antithrombotic medications in patients with ACS undergoing PCI. We will briefly review their mechanisms of action.

\section{Aspirin}

Aspirin permanently and irreversibly blocks cyclooxygenase-1 for the lifespan of the platelet, inhibits the synthesis of thromboxane A2, and is a mainstay of therapy for patients with ACS. It has been shown to improve clinical outcomes ${ }^{13-16}$ and unless contraindicated, should be administered to all patients with ACS, including those undergoing PCI.

\section{Thienopyridines}

Clopidogrel and ticlopidine are structurally related thienopyridines that selectively inhibit adenosine diphosphate (ADP)induced platelet aggregation. They block the binding of ADP to the receptor $\mathrm{P} 2 \mathrm{Y}_{12}$, thus inhibiting activation of the platelet glycoprotein IIb/IIIa complex and platelet activation. ${ }^{17}$ A higher side effect profile of ticlopidine, including diarrhea, nausea, and vomiting in up to $50 \%$ of patients, ${ }^{18}$ and serious hematologic complications such as neutropenia in $1.0 \%$ to $2.4 \%$ of patients, ${ }^{19}$ and thrombotic thrombocytopenic purpura $^{20}$ has led to the primary use of clopidogrel in ACS. Prasugrel, a third generation thienopyridine recently approved by the United States Food and Drug Administration, is a more potent blocker of the platelet $\mathrm{P} 2 \mathrm{Y}_{12}$ receptor than clopidogrel. ${ }^{21}$ However, it has also been associated with increased risk of bleeding particularly in patients $>75$ years of age, in patients who weigh $<60 \mathrm{~kg}$, and in those with a history of transient ischemic attacks or strokes. ${ }^{22}$

\section{Platelet glycoprotein Ilb/llla inhibitors}

Platelet activation leads to a conformational change in the glycoprotein IIb/IIIa receptor. Platelet glycoprotein IIb/IIIa inhibitors bind to and block the conformationally modified receptor, significantly blocking platelet aggregation. These agents can be divided into two groups: ${ }^{23}$ (1) monoclonal antibodies that block the receptor (abciximab), and (2) natural or synthetic compounds that contain a sequence of amino acids recognized by the receptor that act as competitive inhibitors (tirofiban and eptifibatide). While all three agents are indicated as adjunctive agents in patients undergoing PCI, only eptifibatide and tirofiban are approved for use in patients presenting with a non-STEMI who do not undergo an early invasive strategy.

\section{Anticoagulant agents}

Anticoagulant medications are also used alone or in combination with antiplatelet medications in patients with ACS undergoing PCI. These agents include indirect thrombin inhibitors (unfractionated and low-molecular-weight heparin), direct thrombin inhibitors (bivalirudin), and factor Xa inhibitor (fondaparinux).

\section{Indirect thrombin inhibitors}

The heparins, both unfractionated and low molecular weight, are indirect thrombin inhibitors. These agents complex with antithrombin and inhibit fibrin formation, as well as clot production and propagation. Unfractionated heparin has been the primary parenteral anticoagulant used in patients with ACS. It targets the coagulation factors IIa (thrombin) and $\mathrm{Xa}$, with additional but less significant activity against factors IXa, XIa, and XIIa. ${ }^{24}$ Unfractionated heparin inactivates thrombin by forming a complex with thrombin and antithrombin, and inactivates factor Xa through antithrombin. Limitations to unfractionated heparin use include the need for frequent laboratory monitoring, neutralization of heparin's activity by activated platelets, ${ }^{25}$ thrombocytopenia, ${ }^{26}$ platelet aggregation, ${ }^{26}$ a dose-dependent risk of bleeding, ${ }^{27}$ and rebound ischemia following its discontinuation. ${ }^{28-30}$ Moreover, since unfractionated heparin is heterogenous in structure (about one-third of heparin chains contain the high-affinity pentasaccharide required for anticoagulant activity) it is also heterogeneous in its pharmacologic activity. 
Thus, the efficacy and safety of low-molecular-weight heparin has been studied in patients with ACS as an alternative to unfractionated heparin.

Low-molecular-weight heparins are fragments of unfractionated heparin formed via depolymerization reactions that result in polysaccharides of smaller size. Lowmolecular-weight heparin has greater anti-Xa than anti-IIa activity. Importantly, it does not require monitoring of clotting times, is less inhibited by activated platelets, ${ }^{25}$ and is associated with a lower incidence of heparin-induced thrombocytopenia ${ }^{31}$ and rebound ischemia following its discontinuation. ${ }^{29}$ Since it binds less avidly to heparinbinding proteins than does unfractionated heparin, it has better bioavailability and a more predictable anticoagulant response. Of the low-molecular-weight heparins clinically available, enoxaparin is by far the most widely used. It has been shown to decrease ischemic complications in patients treated both conservatively and invasively. ${ }^{32}$

\section{Direct thrombin inhibitors}

The direct thrombin inhibitors, hirudin, argatroban and bivalirudin directly bind to thrombin (factor IIa) without the need for antithrombin. Compared to indirect thrombin inhibitors, they have a more predictable anticoagulant response, do not require anticoagulant monitoring, and are able to inactivate fibrin-bound as well as fluid-phase thrombin. ${ }^{33,34}$ Importantly, because they do not bind to platelet factor 4, they do not cause heparin-induced thrombocytopenia. Hirudin and argatroban are approved for the treatment of patients with heparin-induced thrombocytopenia; ${ }^{35,36}$ bivalirudin is approved as an alternative to heparin in patients with ACS and in patients undergoing PCI.

\section{Factor Xa inhibitor}

Fondaparinux is a synthetic analog of the antithrombinbinding pentasaccharide sequence found in heparin. It is the only selective factor $\mathrm{Xa}$ inhibitor available for clinical use. It binds to and produces a conformational change in antithrombin, markedly increasing its anti-factor Xa activity, but has no activity against thrombin. Fondaparinux does not require monitoring of coagulation, which results in more predictable and sustained anticoagulation compared to heparin. Additionally, since it does not bind to platelets or to platelet factor 4 , it does not cause heparin-induced thrombocytopenia. Because it is cleared by the kidneys, it is contra-indicated in patients with a $\mathrm{CrCl}<30 \mathrm{ml} / \mathrm{min}$. The American College of Cardiology/American Heart Association (ACC/AHA) recommends its use for patients with ACS who are undergoing an early invasive or conservative strategy. ${ }^{37}$ However, in patients undergoing PCI its use has been associated with high rates of catheter thrombosis, making the addition of unfractionated heparin mandatory in this setting. ${ }^{38}$

\section{Reversal of agents}

If a patient does experience a serious bleeding episode, in addition to discontinuation of antithrombotic agents, several antidotes are available for clinical use to help stop the bleeding and stabilize the patient. In patients in whom unfractionated heparin has been given protamine sulfate can be administered. Protamine sulfate is administered intravenously at a rate that should not exceed $50 \mathrm{mg}$ over 10 minutes because of the risk of histamine release resulting in hypotension, bradycardia, and bronchospasm. ${ }^{39}$ The newer agents including low-molecular-weight heparin, the factor Xa inhibitor, fondaparinux, and the direct thrombin inhibitors do not have specific antidotes. While protamine sulfate is a specific and effective antidote for unfractionated heparin, it only partially neutralizes the anticoagulant effect of lowmolecular-weight heparin (approximately $60 \%$ of the anticoagulant effect), and therefore its use may result in failure to stop the bleeding. ${ }^{40}$ Recombinant factor VIIa has been shown to reverse the anticoagulant effect of fondaparinux, however, one important caveat is that this reversal effect was shown in healthy volunteers, not in patients with ACS. ${ }^{41}$ In experimental models, recombinant factor VIIa, prothrombin complex concentrates, and desmopressin acetate have all been studied as to their ability to reverse the anticoagulant effect of the direct thrombin inhibitors. ${ }^{39}$ Lastly, hemodialysis, hemoperfusion, and plasmapheresis may be indicated in some cases of severe bleeding. ${ }^{42}$

\section{Data from the randomized trials}

Over the last decade, many randomized trials have been performed to evaluate the efficacy and safety of antithrombotic therapies. We will summarize pertinent data regarding their use in patients with ACS undergoing PCI.

\section{Role of thienopyridines}

In trials comparing ticlopidine to clopidogrel in combination with aspirin following intracoronary stent placement, clopidogrel was not only as effective as ticlopidine, but had a superior safety and tolerability profile. ${ }^{43-45}$ These positive findings for clopidogrel, together with the serious risk of neutropenia with ticlopidine, ${ }^{46}$ has led to the virtual discontinuation of ticlopidine administration: used only in the rare patient who is intolerant to clopidogrel. 
It has become increasingly clear that, in addition to aspirin, the early administration of clopidogrel is key since optimal pretreatment with this medication has been shown to significantly influence clinical outcomes in patients with ACS treated both conservatively ${ }^{47}$ and invasively. ${ }^{48,49}$ Hence, clopidogrel carries a Class I (level of evidence: A) indication for all patients with ACS according to the ACC/AHA guidelines. ${ }^{37}$ Moreover, pretreatment (or lack of pretreatment) with clopidogrel influences the decision as to which antithrombotic regimen to choose for patients undergoing PCI. The original study demonstrating the importance of clopidogrel therapy in patients with ACS undergoing PCI was the PCIClopidogrel in Unstable Angina to Prevent Recurrent Events (CURE) study. ${ }^{48}$ Of the 2658 patients undergoing PCI in this study, those who were pre-treated with $300 \mathrm{mg}$ of clopidogrel had a $31 \%$ relative risk reduction in cardiovascular death or myocardial infarction at long-term (8-month) follow-up compared to those treated with placebo $(8.8 \%$ vs $12.6 \%$, $P=0.002)$. Importantly, there was no significant difference in rates of major bleeding between the two groups $(2.7 \%$ vs $2.5 \%, P=0.64)$. The benefit of clopidogrel administration is also evident in ACS patients who require coronary artery bypass surgery (CABG) following diagnostic coronary angiography. An analysis from the Acute Catheterization and Urgent Intervention Triage Strategy (ACUITY) study showed that patients who received clopidogrel prior to CABG had lower rates of the composite endpoint of death, myocardial infarction, or unplanned revascularization at 30 days compared to those who did not receive clopidogrel (12.7\% vs $17.3 \%, P=0.01) .{ }^{50}$ Moreover, there was no difference in rates of post-surgical major bleeding $(50.3 \% \mathrm{vs}$ $50.9 \%, P=0.83)$.

In addition to the length of time prior to PCI the loading dose of clopidogrel is administered, the dosage (conventional $300 \mathrm{mg}$ or high dose $600 \mathrm{mg}$ ) is also important. It has been shown that some patients exhibit incomplete inhibition of ADP-induced platelet aggregation within 24 hours of a $300 \mathrm{mg}$ loading dose of clopidogrel. ${ }^{51}$ Thus, the risks and benefits of administering a higher loading dose of clopidogrel (600 mg) have been examined. In one study, 292 patients were randomized to either a $300 \mathrm{mg}$ or $600 \mathrm{mg}$ loading dose of clopidogrel at least 12 hours prior to PCI. ${ }^{52}$ ADP-induced platelet aggregation was significantly lower in patients who received $600 \mathrm{mg}$ of clopidogrel compared to those who received $300 \mathrm{mg}$ of clopidogrel. Moreover, there were significantly fewer cardiovascular events in the group that received the $600 \mathrm{mg}$ loading dose of clopidogrel compared to the $300 \mathrm{mg}$ loading dose $(5.0 \%$ vs $12.0 \%, P=0.02)$.
The benefit of a higher loading dose of clopidogrel was also seen in the Platelet Responsiveness to Aspirin and Clopidogrel and Troponin Increment after Coronary Intervention in Acute Coronary Lesions (PRACTICAL) trial. ${ }^{53}$ In this trial patients who were randomized to $600 \mathrm{mg}$ of clopidogrel had significantly reduced ADP-induced platelet aggregation compared to those who were randomized to $300 \mathrm{mg}$. However, there was no difference in clinical outcomes at 6 months - the high rate $(69 \%)$ of concomitant platelet glycoprotein IIb/IIIa inhibitor use may have attenuated the effect of the higher loading dose of clopidogrel. The Antiplatelet Therapy for Reduction of Myocardial Damage During Angioplasty (ARMYDA)-2 trial randomized 255 patients undergoing PCI to either a $600 \mathrm{mg}$ loading dose or a $300 \mathrm{mg}$ loading dose of clopidogrel 4 to 8 hours prior to the procedure. ${ }^{54}$ The primary endpoint (a 30-day composite of death, myocardial infarction, or target vessel revascularization) was significantly lower in patients who received the high loading dose of clopidogrel compared to those who received the conventional loading dose ( $4 \%$ vs $12 \%, P=0.041$ ), and was driven by a significantly lower rate of myocardial infarction: on multivariate analysis the high loading dose of clopidogrel was associated with a $50 \%$ risk reduction of infarction (odds ratio [OR] 0.48 , 95\% confidence interval [CI] 0.15-0.97, $P=0.044)$.

Prasugrel, a third generation thienopyridine, has been recently studied in patients with acute coronary syndromes in the Trial to Assess Improvement in Therapeutic Outcomes by Optimizing Platelet Inhibition with Prasugrel-Thrombolysis in Myocardial Infarction (TRITON-TIMI)-38 trial. ${ }^{22}$ In this trial, 13,608 patients with moderate to high risk acute coronary syndromes scheduled to undergo PCI were randomized to prasugrel (60 mg loading dose and a $10 \mathrm{mg}$ daily maintenance dose) or to clopidogrel (300 mg loading dose and a $75 \mathrm{mg}$ daily maintenance dose) for 6 to 15 months. Patients who were randomized to prasugrel were less likely to experience the primary endpoint (a combined endpoint of death, nonfatal myocardial infarction, or nonfatal stroke; $9.9 \%$ vs $12.1 \%$, $P<0.001$ ). However, major bleeding (including fatal bleeding) was significantly increased in patients who received prasugrel compared to clopidogrel $(2.4 \%$ vs $1.8 \%, P=0.03)$. In a prespecified subgroup analysis of patients presenting with STEMI, ${ }^{55}$ prasugrel treatment again was associated with a significant decrease in the primary endpoint $(6.5 \%$ vs $9.5 \%$, $P=0.0017)$, however, there was no difference in rates of major bleeding between patients randomized to prasugrel vs clopidogrel $(1.0 \%$ vs $1.3 \%, P=0.34)$. Lastly, in a separate substudy of patients who underwent coronary artery stenting, patients who were randomized to prasugrel had significant 
decreases not only in the primary endpoint $(9.7 \%$ vs $11.9 \%, P=0.0001)$, but also the rate of stent thrombosis $(1.13 \%$ vs $2.35 \%, P<0.0001) .{ }^{56}$ The TRITON-TIMI 38 trial is a perfect example of the balancing act between achieving improved ischemic outcomes and decreasing bleeding complications, and underscores the importance of patient selection and individualizing antithrombotic therapy.

\section{Role of platelet glycoprotein Ilb/llla inhibitors}

Abciximab was the first platelet glycoprotein IIb/IIIa inhibitor available for clinical use. Several trials showed improved clinical outcomes in patients with ACS undergoing PCI who were treated with abciximab vs control; ${ }^{57-62}$ however, its use was associated with significant bleeding complications in many of these trials. ${ }^{57,60}$ Trials assessing the safety and efficacy of tirofiban and integrilin have shown mixed results with no significant differences in clinical outcomes in some, ${ }^{63,64}$ and improved clinical outcomes in others. ${ }^{65-67}$

An important complication of platelet glycoprotein IIb/IIIa inhibitors that limits widespread use of these agents is the increased risk of bleeding. ${ }^{68}$ Although a meta-analysis of 6 trials, enrolling 31,402 patients with ACS who were not routinely scheduled for early revascularization showed a $9 \%$ reduction in the rate of death or myocardial infarction at 30-day follow-up in patients randomized to platelet glycoprotein IIb/IIIa inhibitors compared with placebo (10.8\% vs $11.8 \%$, OR $0.91,95 \%$ CI $0.84-0.98, P=0.015)$, major bleeding complications were increased in patients who received them $(2.4 \%$ vs $1.4 \%, P<0.0001) .{ }^{69}$ One caveat regarding these results is that the improved clinical outcomes provided by these agents were confined to ACS patients with elevated troponin levels.

Questions remain about the choice of platelet glycoprotein IIb/IIIa inhibitor due to conflicting results from comparative studies. In the Tirofiban and Reopro Give Similar Efficacy Outcomes (TARGET) trial ${ }^{70}$ the primary endpoint (a composite of death, myocardial infarction, or target vessel revascularization at 30 days) occurred more frequently in the patients randomized to tirofiban compared to those randomized to abciximab $(7.6 \%$ vs $6.0 \%, P=0.038)$. However, in the Multicentre Evaluation of Single High Dose Bolus Tirofiban vs Abciximab with Sirolimus-Eluting Stent or Bare Metal Stent in Acute Myocardial Infarction (MULTISTRATEGY) trial, ${ }^{71}$ there was no difference in ST segment resolution between patients treated with abciximab or tirofiban (Relative Risk [RR] 1.02, 97.5\% CI $0.958-1.086, P<0.001$ for noninferiority). Moreover, ischemic and bleeding complications were similar between the groups. Lastly, a recent meta-analysis of randomized trials comparing abciximab vs eptifibatide and tirofiban in primary PCI found no significant differences in angiographic, electrocardiographic or clinical outcomes (including bleeding complications) between abciximab and the use of either eptifibatide or tirofiban. ${ }^{72}$

Because clopidogrel therapy plays a critical therapeutic role in patients with ACS, some investigators have asked whether platelet glycoprotein IIb/IIIa inhibitors add sufficient clinical benefit when superimposed upon a background of aspirin, heparin, and clopidogrel. One of the first studies to examine this question was the Intracoronary Stenting and Antithrombotic Regimen-Rapid Early Action for Coronary Treatment (ISAR-REACT)-2 study. ${ }^{73}$ This study randomized 2022 high-risk patients with ACS undergoing PCI to either abciximab therapy (bolus +12 -hour infusion) or placebo. Importantly, all patients were optimally pretreated with $600 \mathrm{mg}$ of clopidogrel (at least 2 hours prior to the procedure) in addition to aspirin and unfractionated heparin. There was a $25 \%$ relative risk reduction in the primary end point (a composite of death, myocardial infarction, or urgent target vessel revascularization occurring within 30 days) in the patients treated with abciximab (8.9\% vs $11.9 \%$; RR 0.75 , 95\% CI $0.58-0.97, P=0.03)$. Moreover, there were no differences in rates of major or minor bleeding, or in the need for blood transfusion. However, at 30 days a pre-specified analysis showed that the significant benefit was confined to the patients who had elevated troponin levels, a finding consistent with a previously published meta-analysis. ${ }^{69}$

In the Early or Late Intervention in Unstable Angina (ELISA)-2 trial, 328 consecutive patients with ACS were randomized to pretreatment with dual antiplatelet therapy (aspirin and clopidogrel $600 \mathrm{mg}$ ) or triple antiplatelet therapy (aspirin, clopidogrel $300 \mathrm{mg}$, and tirofiban). ${ }^{74}$ The primary endpoint was enzymatic infarct size, with a prespecified secondary endpoint of Thrombolysis in Myocardial Infarction (TIMI) flow on the initial angiogram. Although rates of TIMI 3 flow on the initial angiogram were significantly higher in patients who were treated with triple antiplatelet therapy (67 vs $47 \%, P=0.002$ ), there was no difference in the primary endpoint of enzymatic infarct size (median, interquartile range): $166 \mathrm{IU} / \mathrm{L}(60-349)$ in the triple antiplatelet group vs $193 \mathrm{IU} / \mathrm{L}$ (75-466) in the dual antiplatelet group, $P=0.2$. Additionally, there was no significant difference in bleeding rates between the groups.

More recently, the Early Versus Delayed, Provisional Eptifibatide in Acute Coronary Syndromes (EARLY-ACS) trial compared the safety and efficacy of early, routine 
administration of eptifibatide ( 2 boluses and a 12-hour infusion prior to angiography) to delayed, provisional administration of eptifibatide in 9492 patients with unstable angina or non-STEMI who were undergoing PCI. ${ }^{75}$ Importantly, 75\% of the patients were pretreated with $300 \mathrm{mg}$ of clopidogrel. There was no difference in the primary endpoint (a composite of death, myocardial infarction, recurrent ischemia requiring urgent revascularization, or the occurrence of a thrombotic complication during PCI that required bolus therapy opposite to the initial study group assignment at 96 hours) between the groups $(9.3 \%$ in the early eptifibatide group, and $10.0 \%$ in the delayed eptifibatide group, OR $0.92,95 \%$ CI $0.80-1.06$, $P=0.23$ ). Moreover, there was no difference in the rate of death or myocardial infarction at 30 days between the early and delayed eptifibatide groups, with or without the presence of troponin elevation. However, patients randomized to early eptifibatide had a statistically significant increase in TIMI major hemorrhage $(2.6 \%$ vs $1.8 \%, P=0.02)$, and an increased need for blood transfusions ( $8.6 \%$ vs $6.7 \%, P=0.001)$. Thus, these results indicate that the routine early administration of platelet glycoprotein IIb/IIIa inhibitors in patients with unstable angina and non-STEMI prior to PCI is not recommended. Moreover, in non-STEMI patients who are optimally pre-treated with clopidogrel, the addition of platelet glycoprotein IIb/IIIa inhibitors is unlikely to add significant clinical benefit. Hence, the ACC/AHA guidelines state that for non-STEMI patients in whom an initial invasive approach is selected, it is reasonable to omit the upstream use of a platelet glycoprotein IIb/IIIa inhibitor if bivalirudin is used and if at least $300 \mathrm{mg}$ of clopidogrel was administered at least 6 hours prior to the planned procedure (Class IIa, level of evidence: B). ${ }^{37}$

The data supporting the addition of upstream platelet glycoprotein IIb/IIIa inhibitors to high dose clopidogrel in patients presenting with STEMI is conflicting. In the Bavarian Reperfusion Alternatives Evaluation (BRAVE) 3 trial, ${ }^{76} 8000$ patients with STEMI received a $600 \mathrm{mg}$ loading dose of clopidogrel and were then randomized to upstream abciximab or placebo prior to PCI. There was no difference in the primary endpoint of infarct size between the two groups. Moreover, there was no difference in the composite endpoint of death, recurrent infarction, stroke, or urgent revascularization between those randomized to abciximab compared to placebo (5.0\% vs 3.8\%, $P=0.40)$. In the Ongoing Tirofiban in Myocardial Evaluation (On-TIME) 2 trial, ${ }^{65} 984$ patients with STEMI were randomized to either a high-dose bolus of tirofiban or placebo in addition to high dose clopidogrel (600 mg), aspirin, and heparin. Patients who were pretreated with tirofiban had significantly better ST segment resolution compared to those who received placebo. The combined endpoint of death, recurrent infarction, urgent target vessel revascularization, or blinded bail-out use of tirofiban was significantly decreased in those who received tirofiban compared to placebo $(26.0 \%$ vs $32.9 \%, P=0.020)$, suggesting that further platelet inhibition in addition to high dose clopidogrel is important in patients with STEMI undergoing PCI.

In order to decrease the rates of bleeding complications while still benefiting from their use, several studies have evaluated alternate ways to administer platelet glycoprotein $\mathrm{IIb} / \mathrm{III}$ inhibitors. One such study called the Brief Infusion of Eptifibatide Following Percutaneous Coronary Intervention (BRIEF-PCI) trial examined whether an abbreviated infusion of eptifibatide was safe following a successful, non-emergent PCI. ${ }^{77}$ A total of 624 patients with stable angina, unstable angina, or recent STEMI who underwent successful stenting were randomized to either the standard 18-hour infusion of eptifibatide following the procedure, or an abbreviated infusion of $<2$ hours. The primary endpoint (the incidence of peri-procedural myonecrosis defined as troponin I elevation $>0.26 \mu \mathrm{g} / \mathrm{L}$ ) was similar between the groups (30.1\% in the $<2$-hour group vs $28.3 \%$ in the 18 -hour group, $P<0.012$ for noninferiority). Moreover, the secondary endpoint (30 day incidence of myocardial infarction, death, and target vessel revascularization) was similar between the two groups $(4.5 \%$ vs $4.8 \%, P=1.0)$. Importantly, from a riskbenefit ratio standpoint, the abbreviated infusion ( $<2$-hour) resulted in significantly decreased rates of major bleeding complications compared to the standard 18-hour infusion (1.0\% vs $4.2 \%, P=0.02$ ).

The short-term effects of bolus-only administration of abciximab, tirofiban, and eptifibatide have also been studied. ${ }^{78-82}$ These studies have suggested that bolus-only platelet glycoprotein IIb/IIIa inhibitors are as effective as the standard bolus and infusion protocol, but are associated with better clinical outcomes. Additional trials assessing the role (and perhaps length of administration) of platelet glycoprotein IIb/IIIa inhibitors in ACS patients undergoing PCI in the setting of clopidogrel pretreatment are needed.

\section{Role of heparin}

The benefit of using unfractionated heparin in the treatment of ACS was first documented more than 20 years ago, ${ }^{83}$ and subsequently, its use has been shown to result in a $33 \%$ relative risk reduction in death or myocardial infarction when prescribed in addition to aspirin. ${ }^{84}$ In patients with ACS undergoing an initial invasive strategy, both unfractionated 
heparin and low-molecular-weight heparin carry a Class I indication (level of evidence: A). ${ }^{37}$ However, the limitations of unfractionated heparin as described above have led investigators to explore the use of low-molecular-weight heparin instead. One of the first studies to evaluate low-molecularweight heparin in patients with ACS was the Efficacy and Safety of Subcutaneous Enoxaparin in Non-Q Wave Coronary Events Study Group (ESSENCE) trial. ${ }^{85}$ The ESSENCE trial compared the use of the low-molecular-weight heparin, enoxaparin, to unfractionated heparin in patients with ACS undergoing PCI. Patients randomized to enoxaparin had lower rates of the composite endpoint of death, myocardial infarction, or recurrent angina compared to patients treated with unfractionated heparin at 14 days $(16.6 \%$ vs $19.8 \%$, $P=0.019)$, and at 30 days $(27.9 \%$ vs $32.2 \%, P=0.001)$. Moreover, this benefit was maintained at 1-year follow-up (32.0\% vs $35.7 \%, P=0.002) .{ }^{29}$ The TIMI-IIb trial confirmed the benefit of enoxaparin in patients with ACS. ${ }^{86}$ There was a significant reduction in the primary endpoint (a composite of death, myocardial infarction, or urgent revascularization at 8 days and at 43 days) in patients treated with enoxaparin versus unfractionated heparin $(12.4 \%$ vs $14.5 \%, P=0.048)$. A meta-analysis combining data from both the ESSENCE and TIMI-IIb trials showed a reduction in death and ischemic events for patients receiving enoxaparin at day 8 (OR 0.77 , 95\% CI $0.62-0.95, P=0.02$ ), which persisted through follow-up at 14 days (OR 0.79, 95\%CI 0.65-0.96, $P=0.02$ ) and at 43 days (OR $0.82,95 \%$ CI $0.69-0.97, P=0.02) .{ }^{87}$

The more recent Superior Yield of the New Strategy of Enoxaparin, Revascularization and Glycoprotein IIb/ IIIa inhibitors (SYNERGY) trial which randomized 10,027 high-risk patients with non-STEMI to either enoxaparin or unfractionated heparin prior to an early invasive approach, found no significant difference in the primary endpoint of allcause death or nonfatal myocardial infarction during the first 30 days after randomization between the groups $(14.0 \%$ vs $14.5 \%, P=\mathrm{NS}) .{ }^{88}$ While no differences in the rates of bleeding have been reported in patients receiving unfractionated vs enoxaparin who undergo an initial conservative approach, ${ }^{89,90}$ the SYNGERY trial reported an increase in TIMI major bleeding in patients receiving enoxaparin $(9.1 \%$ vs $7.6 \%$, $P=0.008) .{ }^{88}$ A meta-analysis comparing unfractionated heparin to low-molecular-weight heparin in patients with ACS revealed no significant difference in the risk of major bleeding with the short-term use of both unfractionated heparin vs placebo (OR 1.88, 95\% CI 0.60-5.87, P=0.28) and low molecular weight vs placebo (OR 1.41, 95\% CI 0.62-3.23). However, long-term use of unfractionated heparin was associated with a significant increase in major bleeding (OR 2.26, 95\% CI 1.63-3.14, $P<0.0001)$ which was equivalent to an excess of 12 major bleeds for every 1000 patients treated. ${ }^{90}$ Pooled data from 21,946 patients in 6 trials comparing unfractionated heparin to low-molecular-weight heparin in patients with ACS showed no significant difference in death at 30 days for enoxaparin vs unfractionated heparin $(3.0 \%$ vs $3.0 \%$, OR 1.00 , 95\% CI 0.85-1.17). ${ }^{91}$ However, the combined endpoint of death or nonfatal infarction at 30 days was significantly lower for patients treated with enoxaparin rather than unfractionated heparin (10.1\% vs $11.0 \%$, OR 0.91 , 95\% CI 0.83-0.99). Importantly, there was no significant difference in rates of blood transfusions (OR 1.01, 95\% CI 0.89-1.14) or major bleeding (OR 1.04, 95\% CI 0.83-1.30) at 7 days after randomization.

Nonetheless, the inability to measure the level of anticoagulant therapy with the activated clotting time in patients receiving low-molecular weight-heparin generates reluctance by interventional cardiologists to use it during PCI. The widespread use of low-molecular-weight heparin in ACS patients before angiography, however, makes this issue unavoidable. Guidelines for the use of enoxaparin in the peri-PCI period have been proposed. ${ }^{37,92}$ These guidelines state that if enoxaparin is to be used as the antithrombotic agent during the PCI procedure, no additional amount should be given if the last dose was administered within 8 hours. If the last subcutaneous dose was administered at least 8 to 12 hours earlier, an intravenous dose of $0.3 \mathrm{mg} / \mathrm{kg}$ of enoxaparin should be given. An 8-hour window after the last dose of low-molecular-weight heparin is preferred prior to switching to unfractionated heparin. ${ }^{93}$

A unique treatment strategy using low dose enoxaparin $(0.50 \mathrm{mg} / \mathrm{kg}$ every 12 hours) prior to PCI in conjunction with dual antiplatelet therapy (aspirin and clopidogrel) followed by triple antiplatelet therapy (aspirin, clopidogrel and eptifibatide) during the PCI has been evaluated in a large, single center study. ${ }^{94}$ The analysis included 1400 consecutive patients and found that this treatment strategy was associated with low rates of acute ischemic events (1.8\%), minor bleeding complications (2.1\%), major bleeding complications $(0.1 \%)$, thrombocytopenia $(1.3 \%)$, and major adverse clinical events $(0.4 \%)$; suggesting the need for a randomized clinical trial to further evaluate this approach. ${ }^{94}$

Despite improved bioavailability and predictable weightbased dosing, there are several patient populations where pharmacologic parameters for low-molecular-weight heparin are altered including patients with renal insufficiency, the elderly, and the obese. ${ }^{95}$ Patients who are obese have less lean body mass as a percentage of total body weight, so dosing 
low-molecular-weight heparin according to total body weight can cause supra-therapeutic anticoagulation. A similar problem arises in the elderly who also have less lean body mass (in addition to other complicating factors such as renal insufficiency). Since the kidneys are the primary route of elimination for low-molecular-weight heparin, patients with impaired renal function, particularly with $\mathrm{CrCl}<30 \mathrm{ml} / \mathrm{min}$ are at risk for accumulation of the drug, increased levels of anti-Xa, and increased risk of major bleeding complications. ${ }^{96,97}$ In general, the use of low-molecular-weight heparin should be avoided in patients with $\mathrm{CrCl}<30 \mathrm{ml} / \mathrm{min}$.

\section{Role of factor $\mathrm{Xa}$ inhibitor}

The safety and efficacy of the novel factor Xa inhibitor, fondaparinux, was evaluated in the Organization to Assess Strategies in Acute Ischemic Syndromes (OASIS)-5 trial. ${ }^{38}$ In this trial 20,078 patients with unstable angina or non-STEMI were randomized to enoxaparin $1.0 \mathrm{mg} / \mathrm{kg}$ every 12 hours or to fondaparinux $2.5 \mathrm{mg}$ daily. The primary outcome (a composite of death, myocardial infarction, or refractory ischemia at 9 days) occurred in 5.7\% of those randomized to enoxaparin and $5.8 \%$ of those randomized to fondaparinux (hazard ratio $1.01,95 \%$ CI $0.90-1.13, P=0.007$ for noninferiority). Moreover, major bleeding complications were significantly less in the patients receiving fondaparinux $(2.2 \% \mathrm{vs}$ $4.1 \%, P<0.001)$. However, in the patients who underwent PCI, those who were treated with fondaparinux had a significant increase in rates of catheter thrombosis compared to those treated with enoxaparin $(0.9 \%$ vs $0.4 \%, P=0.001)$ which was believed to be from the inability of fondaparinux to block pre-existing thrombin. Therefore, because of the risk of catheter thrombosis, fondaparinux should not be used as the sole anticoagulant during PCI in patients with STEMI (Class III indication, level of evidence: C); unfractionated heparin should be concomitantly administered. ${ }^{98}$

The use of fondaparinux in patients with non-STEMI and unstable angina who undergo both an initial conservative or invasive management strategy carries a Class I indication (level of evidence: B) according to the ACC/AHA guidelines. ${ }^{37}$ Similar to low-molecular-weight heparin, fondaparinux is excreted by the kidneys and therefore is contraindicated in patients with a $\mathrm{CrCl}<30 \mathrm{ml} / \mathrm{min}^{37}$

\section{Role of bivalirudin}

In addition to low-molecular-weight heparin, bivalirudin has also been studied as a replacement for unfractionated heparin in patients with ACS undergoing PCI and carries a Class I (level of evidence:B) indication for use in these patients. ${ }^{37}$
One of the first studies to evaluate the use of bivalirudin in PCI randomized 4098 patients to receive either unfractionated heparin or bivalirudin during the procedure. ${ }^{99}$ While there was no difference in the primary endpoint (a composite of death, myocardial infarction, abrupt vessel closure, or rapid clinical deterioration of cardiac origin), patients randomized to bivalirudin had significantly lower rates of bleeding compared to patients randomized to unfractionated heparin $(3.8 \%$ vs $9.8 \%, P<0.001)$.

With the introduction of more potent antiplatelet agents like clopidogrel and platelet glycoprotein IIb/IIIa inhibitors, several trials have examined the safety and efficacy of bivalirudin in conjunction with these medications. In a pilot trial called the Comparison of Abciximab Complications with Hirulog for Ischemic Events (CACHET) trial, 268 patients were randomized to receive bivalirudin (with or without abciximab) or abciximab with low-dose weight-adjusted heparin during PCI. ${ }^{100}$ In this study, bivalirudin with planned or provisional abciximab was as safe and effective as low-dose heparin plus abciximab. In a separate trial called the Protection against Post-PCI Microvascular Dysfunction and Post-PCI Ischemia among Anti-Platelet and Anti-Thrombotic AgentsThrombolysis in Myocardial Infarction (PROTECT-TIMI)30 trial, 857 patients with non-STEMI were randomized to one of three regimens following angiography: eptifibatide + reduced-dose unfractionated heparin, eptifibatide + reduced dose low-molecular-weight heparin, or bivalirudin monotherapy. ${ }^{101}$ The primary endpoint, coronary flow reserve, was greater in the bivalirudin arm compared to pooled data from the two different eptifibatide arms (1.43 vs $1.33, P=0.036)$. However, TIMI myocardial perfusion grade was more often normal in patients treated with eptifibatide compared to bivalirudin $(57.9 \%$ vs $50.9 \%, P=0.048)$, and the duration of ischemia on Holter monitoring after PCI was significantly longer in patients treated with bivalirudin (169 min vs $36 \mathrm{~min}$, $P=0.013$ ). Although there was no excess of TIMI major bleeding in patients treated with eptifibatide compared with bivalirudin ( $0.7 \%$ vs $0 \%, P=\mathrm{NS})$, TIMI minor bleeding was increased $(2.5 \%$ vs $0.4 \%, P=0.027)$ as well as blood transfusion requirements ( $4.4 \%$ vs $0.5 \%, P<0.001)$.

The ACUITY study examined the use of bivalirudin in 13,819 moderate-risk and high-risk patients with ACS undergoing an early invasive strategy. ${ }^{102}$ Patients were randomized to one of three regimens: platelet glycoprotein IIb/IIIa inhibitor + unfractionated heparin or low-molecular-weight heparin; platelet glycoprotein IIb/IIIa + bivalirudin; or bivalirudin alone. Bivalirudin + platelet glycoprotein IIb/IIIa inhibitor, as compared to heparin + platelet glycoprotein IIb/IIIa, 
was associated with similar rates of the composite ischemic endpoint of death, myocardial infarction, or unplanned revascularization (7.7\% vs $7.3 \%, P=\mathrm{NS})$; major bleeding $(5.3 \%$ vs $5.7 \%, P=\mathrm{NS}$ ); and the net clinical endpoint of ischemia or major bleeding $(11.8 \%$ vs $11.7 \%, P=\mathrm{NS})$. In addition, bivalirudin alone, as compared to heparin + platelet glycoprotein $\mathrm{IIb} / \mathrm{III}$ inhibitor, was associated with similar rates of the composite ischemic endpoint $(7.8 \%$ vs $7.3 \%, P=0.32)$, and significantly reduced rates of major bleeding $(3.0 \%$ vs $5.7 \%$, $P<0.001)$, and the net clinical endpoint $(10.1 \%$ vs $11.7 \%$, $P=0.02)$. In a subgroup analysis of this trial that evaluated 7789 patients who underwent PCI, there were no differences in the composite endpoint of death, myocardial infarction, unplanned revascularization, or death at one year. ${ }^{103}$ However, there was a significant reduction in major bleeding in those patients who received bivalirudin alone compared to those who received heparin + platelet glycoprotein IIb/IIIa inhibitors (4.0\% vs $7.0 \%, P<0.001)$. In a separate analysis of the ACUITY trial, patients who were switched to bivalirudin from either unfractionated or low-molecular-weight heparin had similar rates of ischemia $(6.9 \%$ vs $7.4 \%, P=0.52)$, but less major bleeding complications $(2.8 \%$ vs $5.8 \%, P<0.01)$, which resulted in improved net clinical outcomes $(9.2 \%$ vs $11.9 \%, P<0.01$ ) compared to those who remained on unfractionated heparin or low-molecular-weight heparin + platelet glycoprotein IIb/IIIa inhibitors. ${ }^{104}$

Lastly, the Harmonizing Outcomes with Revascularization and Stents in Acute Myocardial Infarction (HORIZONSAMI) trial randomized 3602 patients with STEMI to heparin + platelet glycoprotein IIb/IIIa or bivalirudin alone. ${ }^{105}$ Anticoagulation with bivalirudin was associated with a $24 \%$ absolute risk reduction in the net adverse clinical events (major bleeding or major adverse cardiac events including death, re-infarction, target vessel revascularization for ischemia, and stroke) at 30 days (9.2\% vs $12.1 \%$, RR $0.76,95 \%$ CI $0.63-0.92, P=0.0005)$ with a $40 \%$ absolute reduction in major bleeding (4.9\% vs $8.3 \%$, RR $0.60,95 \%$ CI $0.46-0.77, P<0.001)$. One important caveat regarding the results of this trial is that there was an increased risk of acute stent thrombosis within 24 hours in patients treated with bivalirudin $(0.3 \%$ vs $1.3 \%, P<0.001)$. It has been suggested that one contributing factor could have been inadequate pretreatment with clopidogrel. This concern was addressed in a post-hoc analysis of the 7789 patients in the ACUITY trial that underwent PCI: ${ }^{106}$ when clopidogrel was administered prior to the PCI or within 30 minutes after the PCI, bivalirudin therapy alone was associated with similar ischemic outcomes compared to placebo $(8.2 \%$ vs $8.3 \%$,
RR $0.98,95 \%$ CL $0.81-1.20, P=0.88)$. However, in patients who received clopidogrel either $>30$ minutes after the PCI or not at all, there was a significant increase in ischemic events in patients randomized to bivalirudin compared to placebo (14.1\% vs $8.5 \%$, RR $1.66,95 \%$ CI $1.05-2.63, P=0.03)$.

The prevailing theme of the importance of optimal clopidogrel pretreatment is also evident in trials assessing the safety and efficacy of bivalirudin in patients with ACS undergoing PCI. ${ }^{107,108}$ In the Intracoronary Stenting and Antithrombotic Regimen: Rapid Early Action for Coronary Treatment (ISAR-REACT) 3 study, ${ }^{107}$ the use of bivalirudin in patients with stable or unstable angina undergoing PCI was evaluated. In this trial 4570 patients who were optimally pretreated with $600 \mathrm{mg}$ of clopidogrel were randomized to either bivalirudin or unfractionated heparin at the time of the PCI procedure. While there was no difference in the primary endpoint (a composite of death, myocardial infarction, and target vessel revascularization due to myocardial ischemia at 30 days), there was a lower incidence of major bleeding in the bivalirudin group $(4.6 \%$ vs $3.1 \%, P=0.0008)$. In the Randomized Evaluation of PCI Linking Angiomax to Reduced Clinical Events (REPLACE)-2 trial 6010 patients undergoing elective or urgent PCI were randomized to bivalirudin with provisional platelet glycoprotein IIb/IIIa inhibitor, or to heparin with planned platelet glycoprotein IIb/IIIa inhibitor. ${ }^{108}$ Importantly, greater than $84.9 \%$ of patients received pre-treatment with clopidogrel $(26.6 \%$ received clopidogrel $<2$ hours prior to $\mathrm{PCI}$ and $56.7 \%$ received it between 2-48 hours prior of PCI). Similar to the ISAR-REACT 3 study, there was no difference in the primary endpoint of death, myocardial infarction, or urgent repeat revascularization at 30 days, and in-hospital major bleeding rates were significantly less with bivalirudin than the combination of heparin and platelet glycoprotein IIb/IIIa inhibitor $(2.4 \%$ vs $4.1 \%, P<0.001)$.

\section{What agents should be used?}

The combination of a large variety of antithrombotic medications available (Table 1), and the lack of consensus regarding the optimal regimen for any given patient, has resulted in a long list of potential regimens. There must be a balance between choosing the regimen that will minimize the risk of recurrent ischemic events, and one that will minimize the risk of bleeding. ${ }^{9}$ Considering the overall risk-benefit ratio, therefore, is important in the decision-making process since it may guide the physician to choose one particular antithrombotic regimen over another for any given patient. ${ }^{109}$ Several risk assessment algorithms are available to help the physician gauge whether the patient is at high- or low-risk for 
Table I Antithrombotic agents commonly administered to patients with acute coronary syndrome undergoing percutaneous coronary intervention

\section{Antiplatelet}

\section{Aspirin}

Thienopyridine (clopidogrel)

Platelet glycoprotein Ilb/llla inhibitors

\section{Anticoagulant}

Indirect thrombin inhibitors

Unfractionated heparin

Low molecular weight heparin

Direct thrombin inhibitor (bivalirudin)

Factor Xa inhibitor (fondaparinux)

a recurrent cardiac event including the TIMI risk score, ${ }^{110}$ the Global Registry of Acute Coronary Events (GRACE) score, ${ }^{111}$ and the Platelet Glycoprotein IIb/IIIa in Unstable Angina: Receptor Suppression Using Integrilin Therapy (PURSUIT) ${ }^{112}$ (Figure 1). In addition to the risk of a recurrent ischemic event, there are other important factors that should be taken into consideration (Table 2): (1) the risk of bleeding, (2) the timing and dose of clopidogrel prior to PCI (if administered), (3) the timing and dose of low-molecular-weight heparin prior to PCI (if administered), (4) the patient's renal function, and (5) whether the patient has a history of heparin-induced thrombocytopenia, or previous drug reactions.

Recently, the Can Rapid Risk stratification of Unstable Angina Patients Suppress Adverse Outcomes with Early Implementation of the ACC/AHA Guidelines (CRUSADE) bleeding score has been developed and validated. ${ }^{113}$ This score predicts the baseline risk of in-hospital major bleeding and incorporates patient information that is readily available upon admission: patient factors predictive of in-hospital major bleeding are female gender, diabetes, a history of vascular disease, high or low systolic blood pressure, tachycardia, hematocrit $<36 \%$, and renal insufficiency. Advanced age has also been shown to be a risk factor for major bleeding complications. ${ }^{114}$ However, since no current algorithm

\begin{tabular}{|c|c|c|c|}
\hline \multicolumn{2}{|c|}{ TIMI risk score } & \multicolumn{2}{|c|}{ GRACE risk score } \\
\hline & Age Factors & Points \\
\hline Factors & Points & $\mathrm{Age}_{\leq 29}$ & 0 \\
\hline Age $\geq 65$ & 1 & $30-39$ & 0 \\
\hline$\geq 3$ CAD risk factors & 1 & $40-49$ & 18 \\
\hline Known CAD (stenosis $\geq 50 \%$ ) & 1 & $50-59$ & 36 \\
\hline Aspirin use in past 7 days & 1 & $60-69$ & 55 \\
\hline$>1$ episode of rest pain in $<24$ hours & 1 & $70-79$ & 73 \\
\hline \multirow{3}{*}{$\begin{array}{l}\text { Elevated cardiac enzymes } \\
\text { ST deviation } \geq 0.5 \mathrm{~mm}\end{array}$} & 1 & $80-89$ & 91 \\
\hline & 1 & $\geq 90$ & 100 \\
\hline & & $\begin{array}{l}\text { History of CHF } \\
\text { History of MI }\end{array}$ & $\begin{array}{l}24 \\
12\end{array}$ \\
\hline \multicolumn{2}{|c|}{ PURSUIT risk score } & \multicolumn{2}{|l|}{ Resting heart rate (bpm) } \\
\hline Factors & Points & $\begin{array}{l}\leq 49.9 \\
50-69.9\end{array}$ & 3 \\
\hline & Polnts & 70-89.9 & 9 \\
\hline \multirow{5}{*}{$\begin{array}{l}\text { Age (decade) UA and (MI) } \\
50 \\
60 \\
70 \\
80\end{array}$} & & $90-109.9$ & 14 \\
\hline & $8(11)$ & $110-149.9$ & 23 \\
\hline & $9(12)$ & $150-199.9$ & 35 \\
\hline & $11(13)$ & $>200$ & 43 \\
\hline & $12(14)$ & \multicolumn{2}{|l|}{ Systolic blood pressure $(\mathrm{mm} \mathrm{Hg})$} \\
\hline Gender & & $\leq 79.9$ & 24 \\
\hline Male & & $90-99.9$ & 22 \\
\hline Female & $\begin{array}{l}1 \\
0\end{array}$ & $100-119.9$ & 18 \\
\hline Wharet CCS clase & & $\begin{array}{l}120-139.9 \\
140-159.9\end{array}$ & 14 \\
\hline No angina or CCS class I/II & & $\begin{array}{l}140-159.9 \\
160-199.9\end{array}$ & $\begin{array}{l}10 \\
4\end{array}$ \\
\hline CCS class III/IV & 2 & $\geq 200$ & 0 \\
\hline \multirow{4}{*}{$\begin{array}{l}\text { Heart rate }(\mathrm{bpm}) \\
80 \\
100 \\
120\end{array}$} & & ST segment depression & 11 \\
\hline & 0 & \multirow{2}{*}{\multicolumn{2}{|c|}{ Initial serum creatinine (mg/dl) }} \\
\hline & $\begin{array}{l}0 \\
0\end{array}$ & & 1 \\
\hline & & $0.4-0.79$ & 3 \\
\hline & $0.8-1.19$ & 5 \\
\hline 120 & 0 & $1.2-1.59$ & 7 \\
\hline 100 & 0 & $1.6-1.99$ & 9 \\
\hline 80 & 0 & $\begin{array}{l}2-3.99 \\
\geq 4\end{array}$ & $\begin{array}{l}15 \\
20\end{array}$ \\
\hline Signs of heart failure & 2 & & \\
\hline ST depression & 1 & $\begin{array}{l}\text { Elevated cardiac enzymes } \\
\text { No in-hospital PCI }\end{array}$ & $\begin{array}{l}15 \\
14\end{array}$ \\
\hline
\end{tabular}

Figure I The TIMI, PURSUIT, and GRACE risk scores.

Abbreviations: CAD, coronary artery disease; CCS, Canadian Cardiovascular Society; CHF, congestive heart failure; $\mathrm{MI}$, myocardial infarction; PCl, percutaneous coronary intervention. 
Table 2 Key considerations in selecting the optimal antithrombotic regimen for an individual patient

\begin{tabular}{ll}
\hline Risk of recurrent ischemic event & Consider \\
& TIMI risk score \\
& GRACE risk score \\
& PURSUIT risk score \\
Risk of major bleeding & Consider \\
Clopidogrel pretreatment & Yes or no \\
& If yes, determine timing and \\
dose of administration prior \\
to PCI procedure \\
Yes or no \\
If yes, determine timing and \\
dose of administration prior \\
to PCI procedure \\
Yes or no \\
If yes, follow recommended \\
renal dosing
\end{tabular}

Heparin-induced thrombocytopenia Yes or no

If yes, tailor regimen accordingly, use bivalirudin in place of heparin

aintegrilin, fondaparinux and enoxaparin should be avoided in patients with severe renal insufficiency (creatinine-clearance $\leq 30 \mathrm{~mL} / \mathrm{min}$ ).

Abbreviations: CRUSADE, Can Rapid Risk Stratification of Unstable Angina Patients Suppress Adverse Outcomes with Early Implementation of the ACC/AHA Guidelines; ${ }^{112}$ GRACE, Global Registry of Acute Coronary Events; ${ }^{110}$ PURSUIT, Platelet Glycoprotein Ilb/llla in UnstableAngina: Receptor Suppression Using Integrilin Therapy; "' TIMI,Thrombolysis in Myocardial Infarction. ${ }^{109}$ incorporates both ischemic and bleeding risk, creation of a "bleeding risk subscale" has been proposed. ${ }^{115}$ Moreover, these investigators recommend particular anthithrombotic agents by integrating bleeding risk with specified ranges of the TIMI, PURSUIT, and GRACE risk scores that define patients at low (defined as TIMI 0-2, PURSUIT 0-8, GRACE 0-124); moderate (defined as TIMI 3-4, PURSUIT 9-16, GRACE 125-248); and high (defined as TIMI 5-7, PURSUIT 17-25, GRACE 249-372) ischemic risk. We similarly propose an algorithm, but include not only cardiac and bleeding risk, but also whether the patient has been pretreated with clopidogrel (Figure 2). In patients who are pretreated with clopidogrel, there are many acceptable choices for an antithrombotic regimen during PCI, especially when the bleeding risk is low. The more difficult scenario, however, is when the patient has not been pretreated with clopidogrel, and is at high risk for a bleeding complication: in this case, if bivalirudin is used, a loading dose of clopidogrel should be administered as soon as possible in the cardiac catheterization laboratory to decrease the risk of subacute stent thrombosis. Moreover, if a platelet glycoprotein IIb/IIIa inhibitor is needed on a provisional basis, a short-acting agent would be preferable.

\section{Future prospects}

Novel agents primarily used for prevention of venous thromboembolism are currently being investigated for

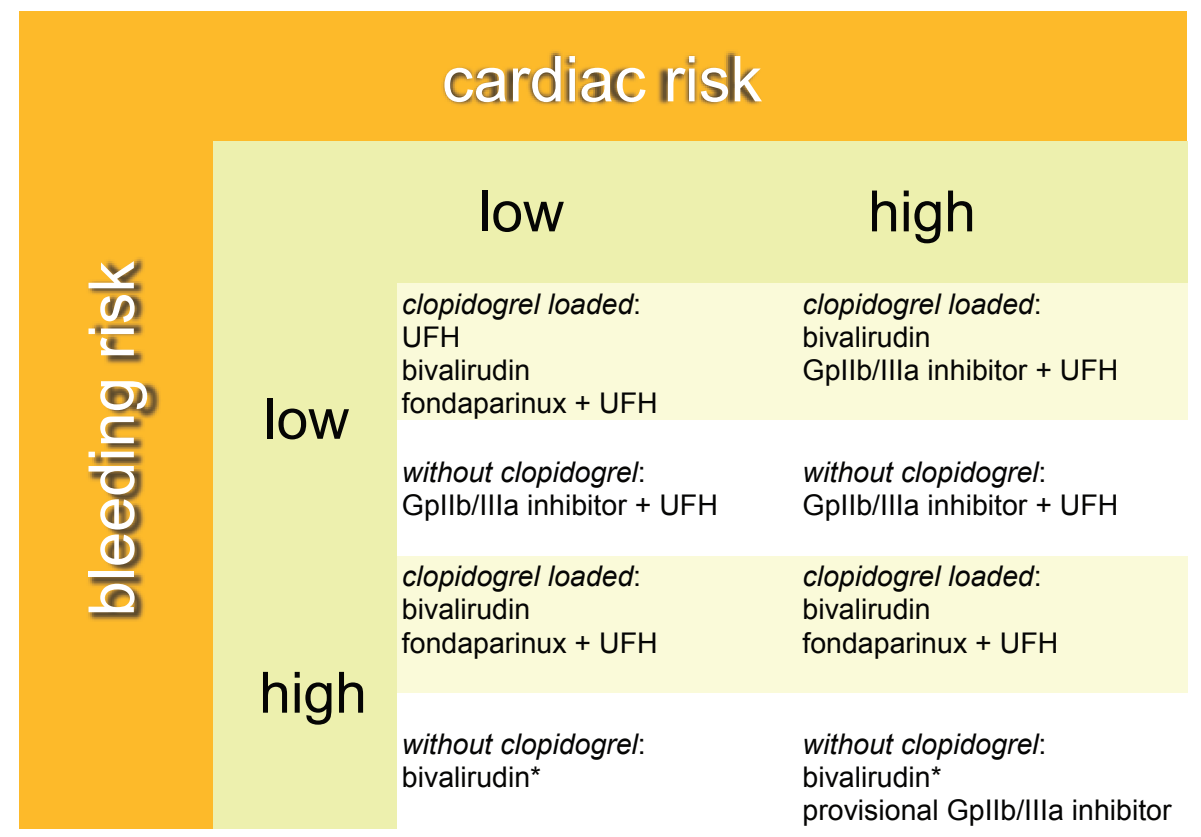

Figure 2 Algorithm for selecting the optimal antithrombotic regimen incorporating cardiac risk, bleeding risk, and clopidogrel pretreatment. In this algorithm it is assumed that all patients have received aspirin.

*If bivalirudin is used, a loading dose of clopidogrel should be given as soon as possible in the cardiac catheterization laboratory to decrease the risk of subacute stent thrombosis. 
use in patients with ACS. ${ }^{116}$ In the Anti-Xa Therapy to Lower Cardiovascular Events in Addition to Aspirin with or without Thienopyridine Therapy in Subjects with Acute Coronary Syndrome-Thrombolysis in Myocardial Infarction (ATLAS ACS-TIMI) 46 trial, rivaroxaban (an oral direct factor Xa inhibitor) was associated with a dose-dependent increase in clinically significant bleeding events, with a trend towards a reduction in the primary efficacy endpoint of death, myocardial infarction, stroke, or severe recurrent ischemia requiring revascularization. ${ }^{117}$ Similar findings have been published regarding apixaban, also an oral direct factor Xa inhibitor evaluated in the Apixaban for Prevention of Acute Ischemic Events (APPRAISE) trial. ${ }^{118}$ Lastly, dabigatron, an oral direct thrombin inhibitor is being studied in the context of secondary prophylaxis after myocardial infarction in the placebo-controlled phase II Randomized Dabigatron Dose Finding Study in Patients with Acute Coronary Syndromes Post Index Event with Additional Risk Factors for Cardiovascular Complications Also Receiving Aspirin and Clopidogrel: Multi-Centre, Prospective, Placebo Controlled, Cohort Dose Escalation (RE-DEEM) trial. ${ }^{119}$

\section{Conclusion}

Selecting the appropriate antithrombotic regimen for patients with ACS undergoing PCI has become a complex task. Treatment guidelines are needed to help physicians incorporate cardiac risk, bleeding risk, and other key factors into their selection of the optimal antithrombotic regimen for an individual patient.

\section{Disclosures}

The authors declare no conflicts of interest.

\section{References}

1. Invasive compared with non-invasive treatment in unstable coronary-artery disease: FRISC II prospective randomised multicentre study. FRagmin and Fast Revascularisation during InStability in Coronary artery disease Investigators. Lancet. 1999;354(9180):708-715.

2. Sabatine MS, Morrow DA, Giugliano RP, et al. Implications of upstream glycoprotein IIb/IIIa inhibition and coronary artery stenting in the invasive management of unstable angina/non-ST-elevation myocardial infarction: a comparison of the Thrombolysis In Myocardial Infarction (TIMI) IIIB trial and the Treat angina with Aggrastat and determine Cost of Therapy with Invasive or Conservative Strategy (TACTICS)-TIMI 18 trial. Circulation. 2004;109(7):874-880.

3. Fox KA, Poole-Wilson PA, Henderson RA, et al. Interventional versus conservative treatment for patients with unstable angina or non-ST-elevation myocardial infarction: the British Heart Foundation RITA 3 randomised trial. Randomized Intervention Trial of unstable Angina. Lancet. 2002;360(9335):743-751.

4. Neumann FJ, Kastrati A, Pogatsa-Murray G, et al. Evaluation of prolonged antithrombotic pretreatment ("cooling-off" strategy) before intervention in patients with unstable coronary syndromes: a randomized controlled trial. JAMA. 2003;290(12):1593-1599.
5. Keeley EC, Boura JA, Grines CL. Primary angioplasty versus intravenous thrombolytic therapy for acute myocardial infarction: a quantitative review of 23 randomised trials. Lancet. 2003;361(9351):13-20.

6. Lloyd-Jones D, Adams R, Carnethon M, et al. Heart disease and stroke statistics - 2009 update: a report from the American Heart Association Statistics Committee and Stroke Statistics Subcommittee. Circulation. 2009;119(3):e21-e181.

7. Fuchs S, Kornowski R, Teplitsky I, et al. Major bleeding complicating contemporary primary percutaneous coronary interventions-incidence, predictors, and prognostic implications. Cardiovasc Revasc Med. 2009; 10(2):88-93.

8. Kinnaird TD, Stabile E, Mintz GS, et al. Incidence, predictors, and prognostic implications of bleeding and blood transfusion following percutaneous coronary interventions. Am J Cardiol. 2003;92(8): 930-935.

9. Doyle BJ, Rihal CS, Gastineau DA, Holmes DR Jr. Bleeding, blood transfusion, and increased mortality after percutaneous coronary intervention: implications for contemporary practice. $J$ Am Coll Cardiol. 2009;53(22):2019-2027.

10. King SB 3rd, Smith SC Jr, Hirshfeld JW Jr, et al. 2007 focused update of the ACC/AHA/SCAI 2005 guideline update for percutaneous coronary intervention: a report of the American College of Cardiology/American Heart Association Task Force on Practice guidelines. J Am Coll Cardiol. 2008;51(2):172-209.

11. Falk E, Shah PK, Fuster V. Coronary plaque disruption. Circulation. 1995;92(3):657-671.

12. Fuster V, Moreno PR, Fayad ZA, Corti R, Badimon JJ. Atherothrombosis and high-risk plaque: part I: evolving concepts. $J$ Am Coll Cardiol. 2005;46(6):937-954.

13. Collaborative meta-analysis of randomised trials of antiplatelet therapy for prevention of death, myocardial infarction, and stroke in high risk patients. BMJ. 2002;324(7329):71-86.

14. Cairns JA, Gent M, Singer J, et al. Aspirin, sulfinpyrazone, or both in unstable angina. Results of a Canadian multicenter trial. $N$ Engl J Med. 1985;313(22):1369-1375.

15. Lewis HD Jr, Davis JW, Archibald DG, et al. Protective effects of aspirin against acute myocardial infarction and death in men with unstable angina. Results of a Veterans Administration Cooperative Study. $N$ Engl J Med. 1983;309(7):396-403.

16. Wallentin LC. Aspirin ( $75 \mathrm{mg} /$ day) after an episode of unstable coronary artery disease: long-term effects on the risk for myocardial infarction, occurrence of severe angina and the need for revascularization. Research Group on Instability in Coronary Artery Disease in Southeast Sweden. J Am Coll Cardiol. 1991;18(7):1587-1593.

17. Foster CJ, Prosser DM, Agans JM, et al. Molecular identification and characterization of the platelet ADP receptor targeted by thienopyridine antithrombotic drugs. J Clin Invest. 2001;107(12):1591-1598.

18. Quinn MJ, Fitzgerald DJ. Ticlopidine and clopidogrel. Circulation. 1999;100(15):1667-1672.

19. Haushofer A, Halbmayer WM, Prachar H. Neutropenia with ticlopidine plus aspirin. Lancet. 1997;349(9050):474-475.

20. Bennett CL, Weinberg PD, Rozenberg-Ben-Dror K, Yarnold PR, Kwaan HC, Green D. Thrombotic thrombocytopenic purpura associated with ticlopidine. A review of 60 cases. Ann Intern Med. 1998; 128(7):541-544.

21. Wiviott SD, Trenk D, Frelinger AL, et al. Prasugrel compared with high loading- and maintenance-dose clopidogrel in patients with planned percutaneous coronary intervention: the Prasugrel in Comparison to Clopidogrel for Inhibition of Platelet Activation and AggregationThrombolysis in Myocardial Infarction 44 trial. Circulation. 2007; 116(25):2923-2932.

22. Wiviott $\mathrm{SD}$, Braunwald $\mathrm{E}, \mathrm{McCabe} \mathrm{CH}$, et al. Prasugrel versus clopidogrel in patients with acute coronary syndromes. $N$ Engl J Med. 2007;357(20):2001-2015.

23. Berkowitz SD. Current knowledge of the platelet glycoprotein IIb/IIIa receptor antagonists for the treatment of coronary artery disease. Haemostasis. 2000;30 Suppl 3:27-43. 
24. Hirsh J, Anand SS, Halperin JL, Fuster V. Guide to anticoagulant therapy: Heparin: a statement for healthcare professionals from the American Heart Association. Circulation. 2001;103(24):2994-3018.

25. Melandri G, Semprini F, Cervi V, et al. Comparison of efficacy of low molecular weight heparin (parnaparin) with that of unfractionated heparin in the presence of activated platelets in healthy subjects. Am J Cardiol. 1993;72(5):450-454.

26. Shantsila E, Lip GY, Chong BH. Heparin-induced thrombocytopenia. A contemporary clinical approach to diagnosis and management. Chest. 2009;135(6):1651-1664.

27. Melloni C, Alexander KP, Chen AY, et al. Unfractionated heparin dosing and risk of major bleeding in non-ST-segment elevation acute coronary syndromes. Am Heart J. 2008;156(2):209-215.

28. Bahit MC, Topol EJ, Califf RM, et al. Reactivation of ischemic events in acute coronary syndromes: results from GUSTO-IIb. Gobal Use of Strategies To Open occluded arteries in acute coronary syndromes. J Am Coll Cardiol. 2001;37(4):1001-1007.

29. Goodman SG, Barr A, Sobtchouk A, et al. Low molecular weight heparin decreases rebound ischemia in unstable angina or non-Q-wave myocardial infarction: the Canadian ESSENCE ST segment monitoring substudy. J Am Coll Cardiol. 2000;36(5):1507-1513.

30. Theroux P, Waters D, Lam J, Juneau M, McCans J. Reactivation of unstable angina after the discontinuation of heparin. $N$ Engl J Med. 1992;327(3):141-145.

31. Warkentin TE, Levine MN, Hirsh J, et al. Heparin-induced thrombocytopenia in patients treated with low-molecular-weight heparin or unfractionated heparin. N Engl J Med. 1995;332(20):1330-1335.

32. Schmidt-Lucke C, Schultheiss HP. Enoxaparin injection for the treatment of high-risk patients with non-ST elevation acute coronary syndrome. Vasc Health Risk Manag. 2007;3(2):221-228.

33. Arora UK, Dhir M. Direct thrombin inhibitors (part 1 of 2). J Invasive Cardiol. 2005;17(1):34-38.

34. Arora UK, Dhir M. Direct thrombin inhibitors (part 2 of 2). J Invasive Cardiol. 2005;17(2):85-91.

35. A comparison of recombinant hirudin with heparin for the treatment of acute coronary syndromes. The Global Use of Strategies to Open Occluded Coronary Arteries (GUSTO) IIb investigators. N Engl J Med. 1996;335(11):775-782.

36. Effects of recombinant hirudin (lepirudin) compared with heparin on death, myocardial infarction, refractory angina, and revascularisation procedures in patients with acute myocardial ischaemia without ST elevation: a randomised trial. Organisation to Assess Strategies for Ischemic Syndromes (OASIS-2) Investigators. Lancet. 1999;353(9151):429-438.

37. Anderson JL, Adams CD, Antman EM, et al. ACC/AHA 2007 guidelines for the management of patients with unstable angina/non ST-elevation myocardial infarction: a report of the American College of Cardiology/American Heart Association Task Force on Practice Guidelines (Writing Committee to Revise the 2002 Guidelines for the Management of Patients With Unstable Angina/Non ST-Elevation Myocardial Infarction): developed in collaboration with the American College of Emergency Physicians, the Society for Cardiovascular Angiography and Interventions, and the Society of Thoracic Surgeons: endorsed by the American Association of Cardiovascular and Pulmonary Rehabilitation and the Society for Academic Emergency Medicine. Circulation. 2007;116(7):e148-e304.

38. Yusuf S, Mehta SR, Chrolavicius S, et al. Comparison of fondaparinux and enoxaparin in acute coronary syndromes. $N$ Engl $\mathrm{J} \mathrm{Med}$. 2006;354(14):1464-1476.

39. Schulman S, Bijsterveld NR. Anticoagulants and their reversal. Transfus Med Rev. 2007;21(1):37-48.

40. Crowther MA, Berry LR, Monagle PT, Chan AK. Mechanisms responsible for the failure of protamine to inactivate low-molecular-weight heparin. Br J Haematol. 2002;116(1):178-186.

41. Bijsterveld NR, Moons AH, Boekholdt SM, et al. Ability of recombinant factor VIIa to reverse the anticoagulant effect of the pentasaccharide fondaparinux in healthy volunteers. Circulation. 2002;106(20): 2550-2554.
42. Crowther MA, Warkentin TE. Bleeding risk and the management of bleeding complications in patients undergoing anticoagulant therapy: focus on new anticoagulant agents. Blood. 2008;111(10):4871-4879.

43. Bertrand ME, Rupprecht HJ, Urban P, Gershlick AH. Double-blind study of the safety of clopidogrel with and without a loading dose in combination with aspirin compared with ticlopidine in combination with aspirin after coronary stenting: the clopidogrel aspirin stent international cooperative study (CLASSICS). Circulation. 2000;102(6):624-629.

44. Muller C, Buttner HJ, Petersen J, Roskamm H. A randomized comparison of clopidogrel and aspirin versus ticlopidine and aspirin after the placement of coronary-artery stents. Circulation. 2000;101(6): 590-593.

45. Taniuchi M, Kurz HI, Lasala JM. Randomized comparison of ticlopidine and clopidogrel after intracoronary stent implantation in a broad patient population. Circulation. 2001;104(5):539-543.

46. Gent M, Blakely JA, Easton JD, et al. The Canadian American Ticlopidine Study (CATS) in thromboembolic stroke. Lancet. 1989;1(8649):1215-1220.

47. Yusuf S, Zhao F, Mehta SR, Chrolavicius S, Tognoni G, Fox KK. Effects of clopidogrel in addition to aspirin in patients with acute coronary syndromes without ST-segment elevation. $N$ Engl J Med. 2001;345(7):494-502.

48. Mehta SR, Yusuf S, Peters RJ, et al. Effects of pretreatment with clopidogrel and aspirin followed by long-term therapy in patients undergoing percutaneous coronary intervention: the PCI-CURE study. Lancet. 2001;358(9281):527-533.

49. Steinhubl SR, Berger PB, Mann JT 3rd, et al. Early and sustained dual oral antiplatelet therapy following percutaneous coronary intervention: a randomized controlled trial. JAMA. 2002;288(19):2411-2420.

50. Ebrahimi R, Dyke C, Mehran R, et al. Outcomes following pre-operative clopidogrel administration in patients with acute coronary syndromes undergoing coronary artery bypass surgery: the ACUITY (Acute Catheterization and Urgent Intervention Triage strategY) trial. $J$ Am Coll Cardiol. 2009;53(21):1965-1972.

51. Gurbel PA, Bliden KP, Hiatt BL, O’Connor CM. Clopidogrel for coronary stenting: response variability, drug resistance, and the effect of pretreatment platelet reactivity. Circulation. 2003;107(23):2908-2913.

52. Cuisset T, Frere C, Quilici J, et al. Benefit of a 600-mg loading dose of clopidogrel on platelet reactivity and clinical outcomes in patients with non-ST-segment elevation acute coronary syndrome undergoing coronary stenting. J Am Coll Cardiol. 2006;48(7):1339-1345.

53. Yong G, Rankin J, Ferguson L, et al. Randomized trial comparing 600- with 300-mg loading dose of clopidogrel in patients with non-ST elevation acute coronary syndrome undergoing percutaneous coronary intervention: results of the Platelet Responsiveness to Aspirin and Clopidogrel and Troponin Increment after Coronary intervention in Acute coronary Lesions (PRACTICAL) Trial. Am Heart J. 2009;157(1):60 e61-e69.

54. Patti G, Colonna G, Pasceri V, Pepe LL, Montinaro A, Di Sciascio G. Randomized trial of high loading dose of clopidogrel for reduction of periprocedural myocardial infarction in patients undergoing coronary intervention: results from the ARMYDA-2 (Antiplatelet therapy for Reduction of MYocardial Damage during Angioplasty) study. Circulation. 2005;111(16):2099-2106.

55. Montalescot G, Wiviott SD, Braunwald E, et al. Prasugrel compared with clopidogrel in patients undergoing percutaneous coronary intervention for ST-elevation myocardial infarction (TRITON-TIMI 38): double-blind, randomised controlled trial. Lancet. 2009;373(9665): 723-731.

56. Wiviott $\mathrm{SD}$, Braunwald $\mathrm{E}, \mathrm{McCabe} \mathrm{CH}$, et al. Intensive oral antiplatelet therapy for reduction of ischaemic events including stent thrombosis in patients with acute coronary syndromes treated with percutaneous coronary intervention and stenting in the TRITON-TIMI 38 trial: a subanalysis of a randomised trial. Lancet. 2008;371(9621):1353-1363.

57. Use of a monoclonal antibody directed against the platelet glycoprotein $\mathrm{IIb} / \mathrm{III}$ a receptor in high-risk coronary angioplasty. The EPIC Investigation. $N$ Engl J Med. 1994;330(14):956-961. 
58. Platelet glycoprotein IIb/IIIa receptor blockade and low-dose heparin during percutaneous coronary revascularization. The EPILOG Investigators. N Engl J Med. 1997;336(24):1689-1696.

59. Randomised placebo-controlled and balloon-angioplasty-controlled trial to assess safety of coronary stenting with use of platelet glycoproteinIIb/IIIa blockade. Lancet. 1998;352(9122):87-92.

60. Brener SJ, Barr LA, Burchenal JE, et al. Randomized, placebocontrolled trial of platelet glycoprotein IIb/IIIa blockade with primary angioplasty for acute myocardial infarction. ReoPro and Primary PTCA Organization and Randomized Trial (RAPPORT) Investigators. Circulation. 1998;98(8):734-741.

61. Montalescot G, Barragan P, Wittenberg O, et al. Platelet glycoprotein $\mathrm{IIb} / \mathrm{III}$ inhibition with coronary stenting for acute myocardial infarction. N Engl J Med. 2001;344(25):1895-1903.

62. Neumann FJ, Kastrati A, Schmitt C, et al. Effect of glycoprotein $\mathrm{IIb} / \mathrm{III}$ a receptor blockade with abciximab on clinical and angiographic restenosis rate after the placement of coronary stents following acute myocardial infarction. J Am Coll Cardiol. 2000;35(4):915-921.

63. Effects of platelet glycoprotein IIb/IIIa blockade with tirofiban on adverse cardiac events in patients with unstable angina or acute myocardial infarction undergoing coronary angioplasty. The RESTORE Investigators. Randomized Efficacy Study of Tirofiban for Outcomes and REstenosis. Circulation. 1997;96(5):1445-1453.

64. van't Hof AW, Ernst N, de Boer MJ, et al. Facilitation of primary coronary angioplasty by early start of a glycoprotein $2 b / 3 a$ inhibitor: results of the ongoing tirofiban in myocardial infarction evaluation (On-TIME) trial. Eur Heart J. 2004;25(10):837-846.

65. Van't Hof AW, Ten Berg J, Heestermans T, et al. Prehospital initiation of tirofiban in patients with ST-elevation myocardial infarction undergoing primary angioplasty (On-TIME 2): a multicentre, double-blind, randomised controlled trial. Lancet. 2008;372(9638):537-546.

66. Randomised placebo-controlled trial of effect of eptifibatide on complications of percutaneous coronary intervention: IMPACT-II. Integrilin to Minimise Platelet Aggregation and Coronary Thrombosis-II. Lancet. 1997;349(9063):1422-1428.

67. Novel dosing regimen of eptifibatide in planned coronary stent implantation (ESPRIT): a randomised, placebo-controlled trial. Lancet. 2000;356(9247):2037-2044.

68. Horwitz PA, Berlin JA, Sauer WH, Laskey WK, Krone RJ, Kimmel SE. Bleeding risk of platelet glycoprotein IIb/IIIa receptor antagonists in broad-based practice (results from the Society for Cardiac Angiography and Interventions Registry). Am J Cardiol. 2003;91(7):803-806.

69. Boersma E, Harrington RA, Moliterno DJ, et al. Platelet glycoprotein IIb/IIIa inhibitors in acute coronary syndromes: a meta-analysis of all major randomised clinical trials. Lancet. 2002;359(9302): 189-198.

70. Topol EJ, Moliterno DJ, Herrmann HC, et al. Comparison of two platelet glycoprotein IIb/IIIa inhibitors, tirofiban and abciximab, for the prevention of ischemic events with percutaneous coronary revascularization. N Engl J Med. 2001;344(25):1888-1894.

71. Valgimigli M, Campo G, Percoco G, et al. Comparison of angioplasty with infusion of tirofiban or abciximab and with implantation of sirolimus-eluting or uncoated stents for acute myocardial infarction: the MULTISTRATEGY randomized trial. JAMA. 2008;299(15): $1788-1799$.

72. De Luca G, Ucci G, Cassetti E, Marino P. Benefits from small molecule administration as compared with abciximab among patients with ST-segment elevation myocardial infarction treated with primary angioplasty: a meta-analysis. J Am Coll Cardiol. 2009;53(18):1668-1673.

73. Kastrati A, Mehilli J, Neumann FJ, et al. Abciximab in patients with acute coronary syndromes undergoing percutaneous coronary intervention after clopidogrel pretreatment: the ISAR-REACT 2 randomized trial. JAMA. 2006;295(13):1531-1538.

74. Rasoul S, Ottervanger JP, de Boer MJ, et al. A comparison of dual vs triple antiplatelet therapy in patients with non-ST-segment elevation acute coronary syndrome: results of the ELISA-2 trial. Eur Heart $J$. 2006;27(12):1401-1407.
75. Giugliano RP, White JA, Bode C, et al. Early versus delayed, provisional eptifibatide in acute coronary syndromes. N Engl J Med. 2009;360(21): 2176-2190.

76. Mehilli J, Kastrati A, Schulz S, et al. Abciximab in patients with acute ST-segment-elevation myocardial infarction undergoing primary percutaneous coronary intervention after clopidogrel loading: a randomized double-blind trial. Circulation. 2009;119(14):1933-1940.

77. Fung AY, Saw J, Starovoytov A, et al. Abbreviated infusion of eptifibatide after successful coronary intervention The BRIEF-PCI (Brief Infusion of Eptifibatide Following Percutaneous Coronary Intervention) randomized trial. J Am Coll Cardiol. 2009;53(10):837-845.

78. Bertrand OF, De Larochelliere R, Rodes-Cabau J, et al. A randomized study comparing same-day home discharge and abciximab bolus only to overnight hospitalization and abciximab bolus and infusion after transradial coronary stent implantation. Circulation. 2006;114(24): 2636-2643.

79. Marmur JD, Mitre CA, Barnathan E, Cavusoglu E. Benefit of bolus-only platelet glycoprotein IIb/IIIa inhibition during percutaneous coronary intervention: insights from the very early outcomes in the Evaluation of 7E3 for the Prevention of Ischemic Complications (EPIC) trial. Am Heart J. 2006;152(5):876-881.

80. Marmur JD, Poludasu S, Agarwal A, Manjappa N, Cavusoglu E. Highdose tirofiban administered as bolus-only during percutaneous coronary intervention. J Invasive Cardiol. 2008;20(2):53-58.

81. Marmur JD, Poludasu S, Agarwal A, et al. Bolus-only platelet glycoprotein IIb-IIIa inhibition during percutaneous coronary intervention. J Invasive Cardiol. 2006;18(11):521-526.

82. Marmur JD, Poludasu S, Lazar J, Cavusoglu E. Long-term mortality after bolus-only administration of abciximab, eptifibatide, or tirofiban during percutaneous coronary intervention. Catheter Cardiovasc Interv. 2009;73(2):214-221.

83. Theroux P, Ouimet H, McCans J, et al. Aspirin, heparin, or both to treat acute unstable angina. $N$ Engl J Med. 1988;319(17):1105-1111.

84. Oler A, Whooley MA, Oler J, Grady D. Adding heparin to aspirin reduces the incidence of myocardial infarction and death in patients with unstable angina. A meta-analysis. JAMA. 1996;276(10):811-815.

85. Cohen M, Demers C, Gurfinkel EP, et al. A comparison of lowmolecular-weight heparin with unfractionated heparin for unstable coronary artery disease. Efficacy and Safety of Subcutaneous Enoxaparin in Non-Q-Wave Coronary Events Study Group. N Engl J Med. 1997;337(7):447-452.

86. Antman EM, McCabe CH, Gurfinkel EP, et al. Enoxaparin prevents death and cardiac ischemic events in unstable angina/non-Q-wave myocardial infarction. Results of the thrombolysis in myocardial infarction (TIMI) 11B trial. Circulation. 1999;100(15):1593-1601.

87. Antman EM, Cohen M, Radley D, et al. Assessment of the treatment effect of enoxaparin for unstable angina/non-Q-wave myocardial infarction. TIMI 11B-ESSENCE meta-analysis. Circulation. 1999; 100(15):1602-1608.

88. Ferguson JJ, Califf RM, Antman EM, et al. Enoxaparin vs unfractionated heparin in high-risk patients with non-ST-segment elevation acute coronary syndromes managed with an intended early invasive strategy: primary results of the SYNERGY randomized trial. JAMA. 2004;292(1):45-54.

89. de Lemos JA, Blazing MA, Wiviott SD, et al. Enoxaparin versus unfractionated heparin in patients treated with tirofiban, aspirin and an early conservative initial management strategy: results from the A phase of the A-to-Z trial. Eur Heart J. 2004;25(19):1688-1694.

90. Eikelboom JW, Anand SS, Malmberg K, Weitz JI, Ginsberg JS, Yusuf S. Unfractionated heparin and low-molecular-weight heparin in acute coronary syndrome without ST elevation: a meta-analysis. Lancet. 2000;355(9219):1936-1942.

91. Petersen JL, Mahaffey KW, Hasselblad V, et al. Efficacy and bleeding complications among patients randomized to enoxaparin or unfractionated heparin for antithrombin therapy in non-ST-Segment elevation acute coronary syndromes: a systematic overview. JAMA. 2004;292(1):89-96. 
92. Bassand JP, Hamm CW, Ardissino D, et al. Guidelines for the diagnosis and treatment of non-ST-segment elevation acute coronary syndromes. Eur Heart J. 2007;28(13):1598-1660.

93. Collet JP, Montalescot G, Lison L, et al. Percutaneous coronary intervention after subcutaneous enoxaparin pretreatment in patients with unstable angina pectoris. Circulation. 2001;103(5):658-663.

94. Denardo SJ, Davis KE, Tcheng JE. Effectiveness and safety of reduced-dose enoxaparin in non-ST-segment elevation acute coronary syndrome followed by antiplatelet therapy alone for percutaneous coronary intervention. Am J Cardiol. 2007;100(9):1376-1382.

95. Clark NP. Low-molecular-weight heparin use in the obese, elderly, and in renal insufficiency. Thromb Res. 2008;123 Suppl 1:S58-S61.

96. Lim W, Dentali F, Eikelboom JW, Crowther MA. Meta-analysis: low-molecular-weight heparin and bleeding in patients with severe renal insufficiency. Ann Intern Med. 2006;144(9):673-684.

97. Nutescu EA, Spinler SA, Wittkowsky A, Dager WE. Low-molecularweight heparins in renal impairment and obesity: available evidence and clinical practice recommendations across medical and surgical settings. Ann Pharmacother. 2009;43(6):1064-1083.

98. Antman EM, Hand M, Armstrong PW, et al. 2007 focused update of the ACC/AHA 2004 guidelines for the management of patients with ST-elevation myocardial infarction: a report of the American College of Cardiology/American Heart Association Task Force on Practice Guidelines. J Am Coll Cardiol. 2008;51(2):210-247.

99. Bittl JA, Strony J, Brinker JA, et al. Treatment with bivalirudin (Hirulog) as compared with heparin during coronary angioplasty for unstable or postinfarction angina. Hirulog Angioplasty Study Investigators. N Engl J Med. 1995;333(12):764-769.

100. Lincoff AM, Kleiman NS, Kottke-Marchant K, et al. Bivalirudin with planned or provisional abciximab versus low-dose heparin and abciximab during percutaneous coronary revascularization: results of the Comparison of Abciximab Complications with Hirulog for Ischemic Events Trial (CACHET). Am Heart J. 2002;143(5):847-853.

101. Gibson CM, Morrow DA, Murphy SA, et al. A randomized trial to evaluate the relative protection against post-percutaneous coronary intervention microvascular dysfunction, ischemia, and inflammation among antiplatelet and antithrombotic agents: the PROTECT-TIMI-30 trial. J Am Coll Cardiol. 2006;47(12):2364-2373.

102. Stone GW, McLaurin BT, Cox DA, et al. Bivalirudin for patients with acute coronary syndromes. $N$ Engl J Med. 2006;355(21):2203-2216.

103. White HD, Ohman EM, Lincoff AM, et al. Safety and efficacy of bivalirudin with and without glycoprotein $\mathrm{IIb} / \mathrm{III}$ inhibitors in patients with acute coronary syndromes undergoing percutaneous coronary intervention 1-year results from the ACUITY (Acute Catheterization and Urgent Intervention Triage strategY) trial. J Am Coll Cardiol. 2008;52(10):807-814.

104. White HD, Chew DP, Hoekstra JW, et al. Safety and efficacy of switching from either unfractionated heparin or enoxaparin to bivalirudin in patients with non-ST-segment elevation acute coronary syndromes managed with an invasive strategy: results from the ACUITY (Acute Catheterization and Urgent Intervention Triage strategY) trial. J Am Coll Cardiol. 2008;51(18):1734-1741.

105. Stone GW, Witzenbichler B, Guagliumi G, et al. Bivalirudin during primary PCI in acute myocardial infarction. $N$ Engl J Med 2008;358(21):2218-2230.
106. Lincoff AM, Steinhubl SR, Manoukian SV, et al. Influence of Timing of Clopidogrel Treatment on the Efficacy and Safety of Bivalirudin in Patients With Non-ST-Segment Elevation Acute Coronary Syndromes Undergoing Percutaneous Coronary Intervention An Analysis of the ACUITY (Acute Catheterization and Urgent Intervention Triage strategY) Trial. JACC Cardiovasc Interv. 2008;1(6):639-648.

107. Kastrati A, Neumann FJ, Mehilli J, et al. Bivalirudin versus unfractionated heparin during percutaneous coronary intervention. $N$ Engl J Med. 2008;359(7):688-696.

108. Lincoff AM, Bittl JA, Harrington RA, et al. Bivalirudin and provisional glycoprotein IIb/IIIa blockade compared with heparin and planned glycoprotein IIb/IIIa blockade during percutaneous coronary intervention: REPLACE-2 randomized trial. JAMA. 2003;289(7): 853-863

109. Hillis LD, Lange RA. Optimal management of acute coronary syndromes. N Engl J Med. 2009;360(21):2237-2240.

110. Antman EM, Cohen M, Bernink PJ, et al. The TIMI risk score for unstable angina/non-ST elevation MI: A method for prognostication and therapeutic decision making. JAMA. 2000;284(7):835-842.

111. Eagle KA, Lim MJ, Dabbous OH, et al. A validated prediction model for all forms of acute coronary syndrome: estimating the risk of 6-month postdischarge death in an international registry. JAMA. 2004;291(22):2727-2733.

112. Boersma E, Pieper KS, Steyerberg EW, et al. Predictors of outcome in patients with acute coronary syndromes without persistent ST-segment elevation. Results from an international trial of 9461 patients. The PURSUIT Investigators. Circulation. 2000;101(22):2557-2567.

113. Subherwal S, Bach RG, Chen AY, et al. Baseline risk of major bleeding in non-ST-segment-elevation myocardial infarction: the CRUSADE (Can Rapid risk stratification of Unstable angina patients Suppress ADverse outcomes with Early implementation of the ACC/AHA Guidelines) Bleeding Score. Circulation. 2009;119(14): 1873-1882.

114. Lopes RD, Alexander KP, Manoukian SV, et al. Advanced age, antithrombotic strategy, and bleeding in non-ST-segment elevation acute coronary syndromes: results from the ACUITY (Acute Catheterization and Urgent Intervention Triage Strategy) trial. J Am Coll Cardiol. 2009;53(12):1021-1030.

115. Diez JG, Cohen M. Balancing myocardial ischemic and bleeding risks in patients with non-ST-segment elevation myocardial infarction. Am J Cardiol. 2009;103(10):1396-1402.

116. Zikria JC, Ansell J. Oral anticoagulation with factor Xa and thrombin inhibitors: on the threshold of change. Curr Opin Hematol. 2009.

117. Mega JL, Braunwald E, Mohanavelu S, et al. Rivaroxaban versus placebo in patients with acute coronary syndromes (ATLAS ACS-TIMI 46): a randomised, double-blind, phase II trial. Lancet. 2009;374(9683):29-38.

118. Alexander JH, Becker RC, Bhatt DL, et al. Apixaban, an oral, direct, selective factor Xa inhibitor, in combination with antiplatelet therapy after acute coronary syndrome: results of the Apixaban for Prevention of Acute Ischemic and Safety Events (APPRAISE) trial. Circulation. 2009;119(22):2877-2885.

119. Steffel J, Luscher TF. Novel anticoagulants in clinical development: focus on factor Xa and direct thrombin inhibitors. J Cardiovasc Med (Hagerstown). 2009;10(8):616-623.
Vascular Health and Risk Management

\section{Publish your work in this journal}

Vascular Health and Risk Management is an international, peerreviewed journal of therapeutics and risk management, focusing on concise rapid reporting of clinical studies on the processes involved in the maintenance of vascular health; the monitoring, prevention and treatment of vascular disease and its sequelae; and the involvement of

\section{Dovepress}

metabolic disorders, particularly diabetes. This journal is indexed on PubMed Central and MedLine. The manuscript management system is completely online and includes a very quick and fair peer-review system, which is all easy to use. Visit http://www.dovepress.com/ testimonials.php to read real quotes from published authors. 